Article

\title{
Tangible and Intangible Boundaries: The Case of Baoshan Port-City Interface in Shanghai
}

\author{
Yueyue Zhang * and Peter Martin Ache \\ Department of Geography, Planning and Environment, Radboud University, The Netherlands; \\ E-Mails: y.zhang@fm.ru.nl (Y.Z.), p.ache@fm.ru.nl (P.M.A.) \\ * Corresponding author
}

Submitted: 30 January 2021 | Accepted: 7 April 2021 | Published: 27 July 2021

\begin{abstract}
Instead of stressing that port cities are characterised by institutional fragmentations with many resulting conflicts, we claim that port cities might be highly constructive in terms of changing tangible and intangible boundaries. To capture this quality, we use the concept of 'penumbral,' a combination of perceptional aspects as well as tangible and intangible spatial constellations. This perspective is applied in the case of the Shanghai Baoshan port-city interface through the investigation of the changing tangible and intangible boundaries, and how planning relates to boundary changes in a context of spatial, industrial, and institutional multi-layered structures. Tangible refers to physical boundaries between the port and urban structure or district, while intangible refers to immaterial boundaries created by actors' views on ports. Based on planning documents, direct observations, and 17 in-depth semi-structured interviews with local governments, port authority, planning departments, and companies, we find that one can indeed speak of penumbral boundaries, based on port-related values and ideas, and particularly on perceptions of the port and port businesses. Those perceptions are the initial power of changing and, following the idea of penumbral boundaries, blurring tangible and intangible boundaries. Finally, we suggest that, following the idea of penumbral boundaries, planning can play a stronger role in connecting the port and the city by first investigating how actors view the port and port businesses carefully, paying full attention to the specific relational context before formulating plans in the usual manner.
\end{abstract}

\section{Keywords}

Baoshan; institutional development; multi-layered structures; penumbral; port-city interface; Shanghai; tangible and intangible boundaries

\section{Issue}

This article is part of the issue "Planning for Porosity: Exploring Port City Development through the Lens of Boundaries and Flows" edited by Carola Hein (Delft University of Technology, The Netherlands).

(C) 2021 by the authors; licensee Cogitatio (Lisbon, Portugal). This article is licensed under a Creative Commons Attribution 4.0 International License (CC BY).

\section{Introduction}

Paasi (2010, p. 2300) states that "one special profession or group of advocates who are faced with the fragmented complexity of regions today are planners." Indeed, this fragmented complexity is what the port city planners are facing at the port-city interface, the redevelopment of which has been a prominent topic for decades (Hoyle, 2000) and continues attracting planners' attention (Hein, 2016; van den Berghe \& Daamen, 2020). This article analyses the changing borders or boundarieswe use both words interchangeably-of the port-city interface and tries to understand how various stakeholders and planning institutions deal with the fragmented boundaries between the port and the city.

The port-city interface refers to a vacant space at the geographical frontier between port-owned land and urban zones (Hayuth, 1982). This vacant space was left by the previous harbour as a result of the port downstream movement to the open sea. Currently, this abandoned 
area has experienced or is experiencing a transition process from focusing on harbour functions to focusing on urban or mixed port and urban uses. The port-city interface reflects the complexity of competition and complementarity between ports and cities (Association Internationale Villes et Ports, 2015), and provides a precious opportunity to sufficiently understand the aspect of boundaries.

Boundaries between the port and the city were first studied by researchers as tangible and intangible boundaries, which concern the spatial aspects and the functional aspects of port cities, respectively (Hesse, 2013; Müller, 2016). Nowadays, the institutional and administrative aspects of the port city boundaries have begun to attract scholars' attention. Teschner (2019) used case studies of seven port cities in Spain, Greece, and Israel to point out that there are no clear boundaries between ports and cities. This is because in terms of land ownership and land use rights, the port and the city are two entities that have a mutual interest relationship and are difficult to separate. At the same time, the uneven distribution of power also causes constant changes in the boundaries between ports and cities. Quite often, the Port Authority is stronger than the municipal government, which makes it difficult for some urban spatial plans to be implemented. Moreover, the institutional and administrative fragmentation of cities and ports has shaped the port's image as 'a city within a city,' which has exacerbated borders between ports and cities (Teschner, 2019; see also Hein, 2019; Hesse, 2018; Moretti, 2017; van den Berghe, 2018).

However, previous studies have seldomly comprehensively investigated the tangible and intangible boundaries of port cities from the spatial, functional, and institutional perspective, and have paid less attention to planning in border changes in port cities. This article attempts to fill the gap through investigating the research question: Based on the spatial, industrial, and institutional development at the port-city interface, how have tangible and intangible borders changed and how does urban planning relate to border changes? Tangible boundaries refer to physical borders between the port and urban structure or district, while intangible borders reflect immaterial boundaries created by actors' views on ports. Shanghai Baoshan is selected as a case to answer the research question. Through analysing related plans and 17 in-depth interviews with planners and companies, we contribute to the theoretical understanding of relations between boundaries and planning and empirical planning of the port-city interface.

The structure of this article is as follows: Section 2 is the theoretical basis focusing on theories related to boundaries in governance and planning, and the port-city interface. Additionally, the spatial, industrial, and institutional elements related to tangible and intangible boundaries between the port and the city are proposed. Section 3 presents empirical findings, which first briefly describes the research method and the back- ground of the Baoshan port-city interface, and then analyses the changing of tangible and intangible boundaries and planning in border changes. The conclusion, Section 4, summarises the role of planning in changing tangible and intangible borders at the port-city interface through the refinement and generalisation of the research case study results.

\section{Conceptual Framework}

When contributing to a thematic issue on "Planning for Porosity: Exploring Port City Development through the Lens of Boundaries and Flows," one is confronted with a set of concepts (or lenses) right at the start: porosity, boundary, flow. In what follows, we first address those by outlining some central positions which are used for the interpretation of results. This is followed by conceptual positions regarding the port-city interface.

\subsection{Boundaries in Governance and Planning}

Within the field of geography and planning, which constitutes the academic point of reference for the authors of this article, the scientific discussion regarding 'boundaries' has taken quite some shifts over past decades, resulting in a paradox at least with respect to planning. Using here the work by Paasi and Zimmerbauer (2016), which stems from the field of border studies:

We argue that the rise of the relational approach in planning is a fitting example of policy transfer, and embracing this thinking causes a 'planning paradox': in strategic planning, planners need to think increasingly in terms of open, porous borders despite the fact that in concrete planning activities, politics, and governance the region continues to exist largely in the form of bounded and territorial political units. (Paasi \& Zimmerbauer, 2016, p. 1)

As Paasi and Zimmerbauer (2016) emphasise, the border has to be seen as a complex and 'context and practice bound' phenomenon. In their attempt to create or shape relations, locally and/or globally, various actors, from businesses to administrations, as natural people but also including institutional actors, construct and deconstruct borders or 'bounded entities.' They do this partly strategically and partly spontaneously, as can also be seen from the historic periods discussed for the case of Shanghai. Paasi and Zimmerbauer (2016) continue:

We then extend the idea... and argue that borders in planning could be better understood as 'penumbral' borders rather than porous, since they are not solely either 'hard' boundary lines or 'fuzzy borderscapes,' but typically manifest themselves only in certain practices. More generally, our observations suggest that the relational character and possible 'boundedness' of regions is inevitably a phenomenon that 
is multilayered and complex as well as context-and practice-bound. (Paasi \& Zimmerbauer, 2016, p. 1)

Penumbral comes from the field of psychology of perception and refers to a soft or blurred outline of a shadow and is as such one of the criteria that enable the visual system to distinguish between shadows and dark spots on the observed object. Transferring this to the question at hand, only when allowing for this soft spot are we able to actually identify the entirety of the object. With a view towards the issue of port city development, it is less so a question of hard boundaries that, at times, can become porous. On the contrary, the practices and also the means of defining boundaries or bounded spaces are fluent and cover many dimensions, like tangible or intangible, as in fences and regulations, and depend on the actual relational activity, or in other words, the actual strategic planning of the port-city interface. Seeing the border as a 'blurred' entity allows actors to shape their respective room of manoeuvres.

The suggestion to consider boundaries rather as 'penumbral' provides a connection with another popular concept in planning - that of soft spaces. Soft spaces, as prominently introduced by Allmendinger and Haughton (2009), shift the scientific attention to new forms of territorial governance, most notably emerging at the scale of urban regions. These new spaces of governance are understood as 'soft' given their fuzzy boundaries, being located in between formal levels of governance. Going a step further, these new spaces of governance are supposed to replace existing territorial governance structures in strategic ways, adding extra layers to an increasingly complex and fragmented governance landscape. Following this understanding, the central perspective rests on practices, or sets of governances, helping to assess a border and develop a clearer identification of how porous a border is and, importantly, in what ways.

The last element relates to flow. Since Castells' (1996) writing on the network society and the 'spaces of flows' within various disciplines, a discussion on the related aspects can be observed. For the topic of boundaries, an interesting proposition comes from Swyngedouw (2004), who conceptually embraced the floating character of space by suggesting 'scalar configurations.' Serving as a bridging figure between environmental studies and social sciences, Swyngedouw (2004, p. 132) notes that "scalar configurations... as well as their discursive and theoretical representation, are... an outcome of the perpetual movement of the flux of socio-spatial and environmental dynamics." Looking at the port-city interface, this interpretation provides a challenging perspective, calling for permanent adjustments to those dynamics. Planning actions need to be highly adaptable and responsive to changing constellations.

Taking all previous paragraphs together for a very first conceptual conclusion, thus, the port-city interface can be understood as a floating scalar configuration which is based on the continuous construction, re-construction, or de-construction of tangible and intangible boundaries, a penumbral zone that helps both the city and the harbour to 'see' and respond to internal and external challenges and to plan and develop the port-city interface in a consistent and responsive manner.

\subsection{Theory of the Port-City Interface}

It can be seen from the above discussions that the port city is highly constructive. The relationship between the port and the city is changing all the time and the boundary between them is constantly formed, disappearing, and re-forming again. This article assumes that the port-city interface fully reflects this transformed and complex relationship between the port and the city. There are two main reasons for this. First, the transformation of old port areas was urban scholars' focus. This corresponding research is classified as 'Urbanization of Old Port Areas' (Daamen, 2010; H. Wang \& Luan, 2014). Hayuth (1982) noted that in the process of urbanisation, the development of areas adjacent to the waterfront was considered but the development of maritime activities located within the waterfront was ignored. Hayuth (1982) further claimed that the intersection between the city and the port was seriously neglected and defined this interaction as the port-city interface: a vacant space at the geographical frontier between portowned land and urban zones. The space was left with the previous harbour moving downstream to the sea and is an area under transition between harbour functions and urban uses (Hayuth, 1982). This concept refines the perspective of the waterfront to a flexible and adjustable interface between the port and the city.

Second, the port-city interface can reflect the complex relationships formed by the intertwining of different factors. As reflected in the six-stage model of Hoyle (2000), the interface has witnessed the mutual prosperity of ports and cities from the Middle Ages to the mid-twentieth century, and has witnessed the entire process of the retreat of the port from urban centre, the separation of port and city functions, and the redevelopment of old port areas since the 1960s. It has withstood the scrutiny and test of various factors from the initial technology, economy to later society, environment, politics and laws, and regulations (Hayuth, 1982; Hoyle, 1989; Norcliffe, 1981; Slack, 1980). The institutional separation of port and city management departments that began in the 1990s made the development of the port-city interface more complicated. On the one hand, the port-city interface, as a kind of boundary, blocks certain original connections. On the other hand, it provides great potential for the development of strategic planning to link the port and city administration (Hein, 2011; Moretti, 2017).

Therefore, we focus on the port-city interface to explore the changing boundaries and the role of planning in those changes. The spatial, industrial, and institutional elements of tangible and intangible boundaries in existing literatures are summarised in Table 1. As it 
is claimed that borders are multi-layered (Zimmerbauer, 2011), this comprehensive perspective including spatial, industrial, and institutional aspects offers precious opportunities to investigate border changes in a multilayered context.

\section{Empirical Findings at Shanghai Baoshan Port-City Interface}

To investigate how tangible and intangible borders formed and how planning relates to borders in this process, we apply a qualitative and exploratory case study design (Yin, 2018). The rationale of using a case study is that the understanding of borders and planning requires strong local contextualisation. Moreover, the selected case should be experiencing the port-city interface redevelopment spatially, industrially, and institutionally at an early stage. Cases whose interface transformations have been ongoing for some time and have taken full shape, such as Barcelona and London (Daamen \& Vries, 2013; Hoyle, 2000), are not in our consideration. This article pays attention to the port city of Shanghai, where the corporatisation of the port authority has been advocated institutionally (J. J. Wang \& Slack, 2004) and the port is retreating from the inner city generally $(\mathrm{H}$. Wang, 2014). Specifically, we focus on Baoshan District, whose port-city interface not only manifests the institutional port governance changes, but also underlines the industrial transformations of port-related activities to a larger extent. This is due to its historical base for heavy industry, which is further elaborated in Section 3.1.

Following case study design, the data was mainly collected from three sources: (1) documents including city and port planning documents, port governance laws

Table 1. Elements related to tangible and intangible boundaries between the port and the city.

\begin{tabular}{lll}
\hline Spatial aspects & Intangible borders \\
\hline & S-1 & Fortified fences and walls that need \\
& permission (Hein, 2019; Hesse, 2018; Müller, \\
& $2016 ;$ van den Berghe, 2018) \\
& S-2 \\
& Customs gate (Hein, 2019; Hesse, 2018) \\
& S-3 \\
& Port-related space: previous harbour \\
& infrastructure and architectural design; \\
& docklands; railways (Hein, 2019; Müller, 2016; \\
& Teschner, 2019)
\end{tabular}

Industrial aspects

Institutional aspects
IN-1

Port-related goods (Hein, 2019)

IN-2

Port-related people (Hein, 2019)

IN-3

Port-related activities (Hein, 2019; Müller, 2016; Teschner, 2019)

IN-4

Port-related values and ideas (Hein, 2019; Müller, 2016)

INS-1

Governance: administrative jurisdiction (Hein, 2019; Hesse, 2018; van den Berghe, 2018); governance frameworks and legal systems (Hein, 2019); land ownership; land-use planning; activities allowed in port area; public access (Teschner, 2019)

INS-2

Planning: planning guidelines; goals of politicians; planners; and other stakeholders (Hein, 2019) 
and regulations, and government reports of Shanghai Baoshan; (2) direct observations; and (3) 17 in-depth semi-structured interviews with representatives from local governments, port authority, planning departments, and companies located around the port-city interface. Interviews were conducted from July to September 2019 and were coded through Atlas.ti 8. An initial set of codes were defined based on Table 1 and subsequent codes were complemented by sticking closely to interview data. Using a standard function of Atlas.ti, networks between codes and quotations as well as between different codes were built to explain the changing borders at Baoshan port-city interface in Section 3.2, and planning in border changes in Section 3.3.

\subsection{The Context of Baoshan Port-City Interface}

Baoshan, with an area of 270.99 square kilometres and a population of 2,044,300 (in 2019), is a district located in the North of Shanghai (see Figure 1). Baoshan has Wusong and Luojing, two ports in the east. Wusong Port, developed in the 1880 s, is mainly engaged in international container freight and is the main port area of Shanghai's foreign trade (Compilation Committee of Records of Place Names in Shanghai, 1998; Shanghai Baoshan District Historical Records Compilation Committee, 1996). Luojing Port, built in the 1990s, is Shanghai's bulk cargo terminal and the largest coal transfer hub (Compilation Committee of Records of Place Names in Shanghai, 1998).

A large-scale enterprise cluster has been formed around Wusong and Luojing Ports (Shanghai Baoshan District Local Records Compilation Committee, 1992). It includes China's largest modern steel complexBao Steel-its largest port thermal power plant-the Shidongkou Power Plant-and its supercritical thermal power plant-Huaneng Shidongkou Second Power Plant. The iron and steel industry and the metallurgical industry have become the mainstay industries of Baoshan. Besides, multiple industrial zone and industrial parks have been developed in Baoshan to support its industrial development, for example Baoshan Industrial Park.

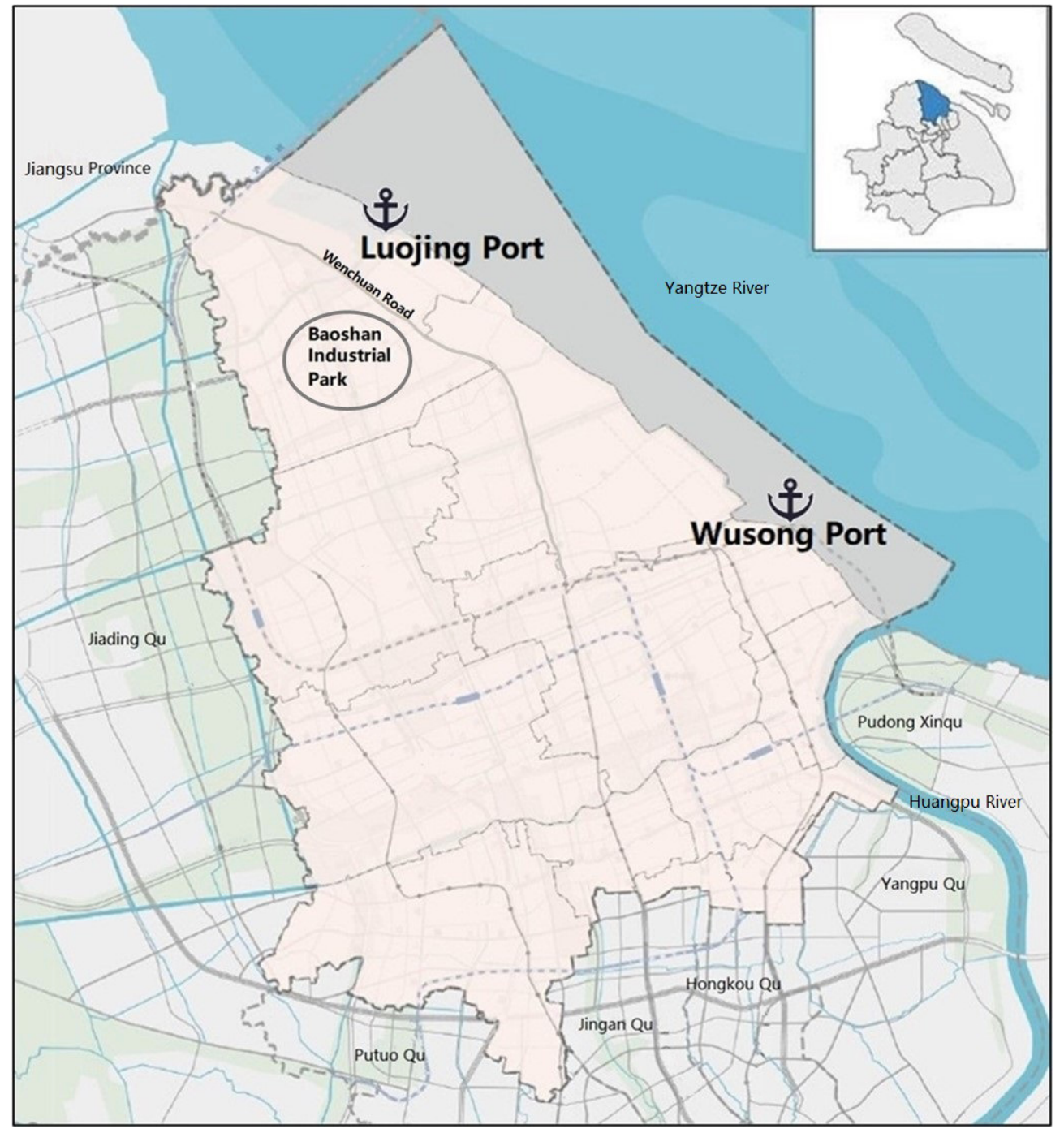

Figure 1. The layout of Baoshan. Source: Authors, modified from Shanghai Baoshan District People's Government and Shanghai Municipal Planning and Natural Resources Bureau (2019). 
With the speeding up of Shanghai's urbanisation, Baoshan has entered a period of industrial transformation and upgrading of heavy industries in the early 21st century (Shanghai Baoshan District People's Government \& Shanghai Municipal Planning and Natural Resources Bureau, 2019). At the same time, ports require a deep sea area because of the increasing ship size. By the time of the opening of Yangshan Deep-Water Port in 2005, a series of port-related industries like steel processing and transportation activities have gradually moved away from Baoshan to other areas in Shanghai. As a result, Baoshan port-city interface was formed at the intersection and vacant area between Wusong and Luojing Ports and the Baoshan urban area. This interface now faces the challenges of redeveloping the abandoned port area with changing boundaries, which is analysed in the following section.

\subsection{The Changing Tangible and Intangible Boundaries}

Through coding the interview data and linking thematic codes to quotations from respondents, the composition of the tangible and intangible boundaries at Baoshan port-city interface can be summarised as in Table 2 . Spatially, we find respondents frequently related 'S-1 fences and walls' to tangible borders. One element which was not listed in Table 1 is the road. In China, roads are regularly used to distinguish territorial borders in planning documents. For instance, Wenchuan Road in Figure 1 is planned as the easternmost border of Baoshan Industrial Park. Regarding intangible borders, 'distances' and 'water' are added as new findings to Table 1. The reasons 'distances' raise intangible borders can be exemplified as follows:

What is the relationship between the port, portrelated industries and our industrial park? It has nothing to do with us. Baoshan Industrial Park, well, Bao Steel as a port-related company is located to the east of Wenchuan Road. But, Wenchuan Road is the Easternmost border of our industrial park. Our industrial park is located to the west of Wenchuan Road and has never been out of Wenchuan Road....This park is generally more than 8 kilometres away from the nearest port, even if the nearest point of this park is half a kilometre away from Luojing Port. (Baoshan Industrial Park manager)

The above quotation indicates that spatial distances, even if it is only half a kilometre away from the port, allow the industrial park manager to build an invisible boundary between the port and the industrial park collaborations. Since this 'half a kilometre' is somewhere to the east of Wenchuan Road, the interviewee expressed confusion about why he was asked to collaborate with companies or ports beyond the park's scope. His reaction implies that the soft intangible border between the port, port-related industries, and the city tends to become hardened because of the tangible border. This is a first interesting finding on border changes in spatial development. 'Water' is tangible, while here it is linked to intangible borders through relating mostly to water functions. Some respondents like urban planners claim that water should be used for real estate and entertainment development instead of for transporting goods. This cracks the port and the city invisibly.

We find that both intangible and tangible borders have relations with industrial development. Port-related goods, people, and activities can create tangible and intangible borders at the same time, as the names 'IN-X' and 'IN-X(Clone)' show. For example, some respondents connect 'port-related people' to intangible borders since they are looking for high-end talent to work with, while harbour workers are always considered as low-end talent. Yet, some respondents linked 'port-related people' to tangible borders because harbour workers are usually living near the harbour and vice versa. If a space is occupied by many harbour workers and people living around the harbour, they label this space as a port area and try to keep distance. Even if this space is not a physical harbour, they still treat it as a port place, as if there are real, tangible borders like fences. These two examples support our finding that not only spatial elements create tangible borders; industrial aspects do raise tangible borders between the port and the city as well.

Reasons for keeping distance from the port can be explained by how respondents look at the port and port businesses, which are listed under 'IN-4-1.' Non-harbour people refer to respondents who are not working on the port and port-related industries, like a Baoshan Industrial Park manager. According to their perceptions, the port is a dirty, polluted, and congested space with crowded cargo transportations, traditional industries, and less educated people. These kinds of negative views or perceptions on ports and port businesses keep respondents away from a space with strong port atmosphere. That formulates another finding that, from an industrial perspective, negative perceptions on ports and port businesses can harden the invisible, soft port atmosphere and finally create tangible, hard borders between the port and the city.

Additionally, we find that these negative perceptions are not much weakened by positive views on ports and port businesses from 'IN-4-2 harbour people' in Table 2, referring to people who are doing businesses related to ports, like the manager from a shipping building company. Why is this? Answers are linked to the institutional aspects. On the one hand, the port makes weaker voices because of the governance framework and land ownership in Shanghai. On the other hand, current planning guidelines lead the port to a much weaker situation and facilitate more negative perceptions on ports and port businesses.

As shown in Table 2, 'INS-1 governance' at Baoshan port-city interface is mainly operated by Shanghai Municipality, Baoshan District Government, and Port 
Authority. The latter refers to a complex of the Ministry of Transport, Shanghai Municipal Transportation Commission-an administrative department under the municipality-and Shanghai International Port (Group) Co. LTD (SIPG) - a state-owned company at the city level. Port land is owned by Shanghai Municipality and SIPG leases it to other companies on behalf of the municipality. Under this governance framework and land ownership, the city governors do not regard the port as a separate entity which needs to be paid extra attention.
One respondent from Shanghai Municipality mentioned that "we pursue the integration of industrial developments and urban developments. We do not talk about the integration of the port and the city." And the port itself is accustomed to accept the city's arrangement and planning without dissent. The port governors even seldomly think of competing with the city for something by taking the port as a relatively equal and independent entity with the city. "We do not have the definition of a port-city interface and the collaboration between the

Table 2. The composition of tangible and intangible boundaries at Baoshan port-city interface.

\begin{tabular}{|c|c|c|}
\hline & Tangible & Intangible \\
\hline Spatial aspects & $\begin{array}{l}\text { S-1 } \\
\text { Fences and walls: iron and steel } \\
\text { fences; blue iron sheet; roads } \\
\text { S-2 } \\
\text { Customs gate } \\
\text { S-3 } \\
\text { Port-related space: docks; } \\
\text { warehouses; berth; crane; } \\
\text { handling machine and so on; } \\
\text { there are no pedestrian roads, } \\
\text { only traffic lanes. }\end{array}$ & $\begin{array}{l}\text { S-4 } \\
\text { Distances: harbour is } 0.5-8 \mathrm{kms} \text { from us } \\
\text { S-5 } \\
\text { Water: functions of water or how to use water }\end{array}$ \\
\hline Industrial aspects & $\begin{array}{l}\text { IN-1 (Clone) } \\
\text { Port-related goods: cargoes } \\
\text { IN-2 (Clone) } \\
\text { Port-related people: harbour } \\
\text { workers; people live around } \\
\text { harbour } \\
\text { IN-3 (Clone) } \\
\text { Port-related activities: large } \\
\text { spaces }\end{array}$ & $\begin{array}{l}\text { IN-1 } \\
\text { Port-related goods: cargoes } \\
\text { IN-2 } \\
\text { Port-related people: logistics workers; low-end talents } \\
\text { IN-3 } \\
\text { Port-related activities: shipbuilding industry; steel processing; } \\
\text { logistics } \\
\text { IN-4 Port-related values and ideas: } \\
\text { IN-4-1 from non-harbour people-dirty; lots of pollution; } \\
\text { cargo transportation; if the harbour stops providing jobs and } \\
\text { serving cities then it does not need to exist; low end } \\
\text { manufacturing; traditional with low technology; low added } \\
\text { value; not matchable with the living environment of inner city; } \\
\text { container trucks exacerbate traffic congestion; transforming } \\
\text { old port areas into houses with sea views is a good option; it is } \\
\text { fine to tear down all old harbour buildings to create new uses; } \\
\text { Industries in Baoshan are related to Baosteel's high-quality } \\
\text { steel and have nothing to do with ports; accommodating } \\
\text { logistics workers in Baoshan means losing high-end talents } \\
\text { IN-4-2 from harbour people: awareness of recognising harbour } \\
\text { industries are traditional industries; accepting that they may } \\
\text { bear certain losses in research and development and } \\
\text { innovation; willingness of applying new technologies like the } \\
\text { intelligentization of port terminals; fear of being marginalised } \\
\text { by new technology or innovation; proactively seek for shipping } \\
\text { talents; pollution is not caused by shipping industry but the } \\
\text { planning of transportation network, because the urban is } \\
\text { also expanding }\end{array}$ \\
\hline
\end{tabular}


Table 2. (Cont.) The composition of tangible and intangible boundaries at Baoshan port-city interface.

\begin{tabular}{ll}
\hline Tangible & Intangible \\
\hline Institutional aspects & INS-1 \\
& Governance: mainly governed by Shanghai Municipality; Port \\
& Authority; Baoshan District Government; Port land is owned by \\
& the municipal government and SIPG leases it to other \\
& companies on behalf of the municipal government
\end{tabular}

INS-2

Planning:

General guidelines: Baoshan Master Plan 2017-2035; 13th

Five-Year Plan (2016-2020) of International Shipping Centre; Shanghai's 13th Five-Year Plan for Comprehensive Transportation;

Goals of stakeholders:

Goals of Shanghai Municipality: pursue the integration of industrial development and urban evolution

Goals of Ministry of Transport: develop Shanghai International Shipping Centre

Goals of Shanghai Municipal Transportation Commission: build and improve the collection and distribution system of the Shanghai International Shipping Centre

Goals of SIPG: become a global multinational terminal operating company to actively participate in domestic and foreign port investment and construction

Goals of Bao Steel: become the world's most competitive steel company and the most valuable listed company; gradually transfer its production capacity from Shanghai to its surrounding cities, in response to Shanghai's environmental protection requirements

Goals of port-related companies like ship-building companies: "Meet environmental requirements and actively use new technologies"

Goals of Baoshan government: "Baoshan will transform from a steel base to international cruise base and to cherry blossom tourism centre (from 'Ganghua,' 'Langhua' to 'Yinghua' in Chinese)"

Goals of urban planners: "The port area is for work and the city is for life, so a space for life should be the main focus of the interface border"

Goals of Baoshan Industrial Park management committee: develop a national strategic emerging industry base and an industrial base representing the high-end level of advanced manufacturing

port and the city. Because the port and the city are originally one unit and we always talk about them together," one respondent from Shanghai Municipal Transportation Commission said. In short, the port loses its independence gradually and makes weaker voices than the city.

Regarding 'INS-2 planning,' the statement that "the port and the city are originally one unit and we always talk about them together" has been verified neither in planning process nor in planning documents. In the planning process, no actor calls to connect the port and the city, though port-related organisations such as SIPG, Bao Steel, and port-related companies are involved. SIPG, as one respondent claimed, "as a state-owned company at city level, our focus is on the development of the 
enterprise itself, and we will not actively consider the functional positioning and matching of the government and assume extra responsibilities." Bao Steel, a stateowned company at the country level, also focuses mostly on its own development. Port-related companies show the awareness of collaborating with and learning from urban companies, but their positivity is recognised only to a limited extent by the city.

In planning documents, general guidelines lead the port development at times to a worsened or contradictory situation. For Wusong Harbour, 'Shanghai's 13th Five-Year Plan (2016-2020) of International Shipping Centre' states that Wusong harbour would transform into an international cruise harbour by changing and upgrading the old industrial park (Shanghai Municipality, 2016a), while traditional port industries and low-capacity port-related industries such as steelmaking and logistics are required to move out of Baoshan in 'Baoshan Master Plan 2017-2035' (Shanghai Baoshan District People's Government \& Shanghai Municipal Planning and Natural Resources Bureau, 2019). Moreover, 'Baoshan Master Plan 2017-2035' plans Wusong as a Shanghai-level sub-centre to focus on the real estate industry. These plans enlarge urban stakeholders' negative perceptions of ports and port businesses. As one urban planner responded, "the port area is for work and the city is for life, so a space for life should be the main focus of the interface border." Another respondent from Baoshan Industrial Park emphasised that "port functions for us are no more than cargo transportations and logistics which bring a lot of pollution and transportation congestion. And they are going to be moved out of Baoshan." In the case of Luojing Port, documents propose redevelopment to connect with the local urban evolution, based on 'Shanghai's 13th Five-Year Plan for Comprehensive Transportation' (Shanghai Municipality, 2016b) and 'Baoshan Master Plan 2017-2035' (Shanghai Baoshan District People's Government \& Shanghai Municipal Planning and Natural Resources Bureau, 2019), which is a positive signal. However, no more details than this sentence are given. Overall, from an institutional perspective, governance and planning strengthen intangible borders between the port and the city.

The above analysis exemplifies border changes from spatial, industrial, and institutional perspectives, respectively. Through our examples, we notice that three aspects are related to each other in border changes. Taking these three aspects as separate layers, our result confirms the declaration from Zimmerbauer (2011) that borders are deeply multi-layered. In order to visualise complicated border changes in multi-layered contexts, a network between codes and respondents' quotations is mapped out in Figure 2. The circle made up of all codes in Figure 2 shows that in the interviewees' minds, borders between ports and cities are more intangible than tangible. The lines between codes and quotations indicate in which way borders are mentioned by respondents.

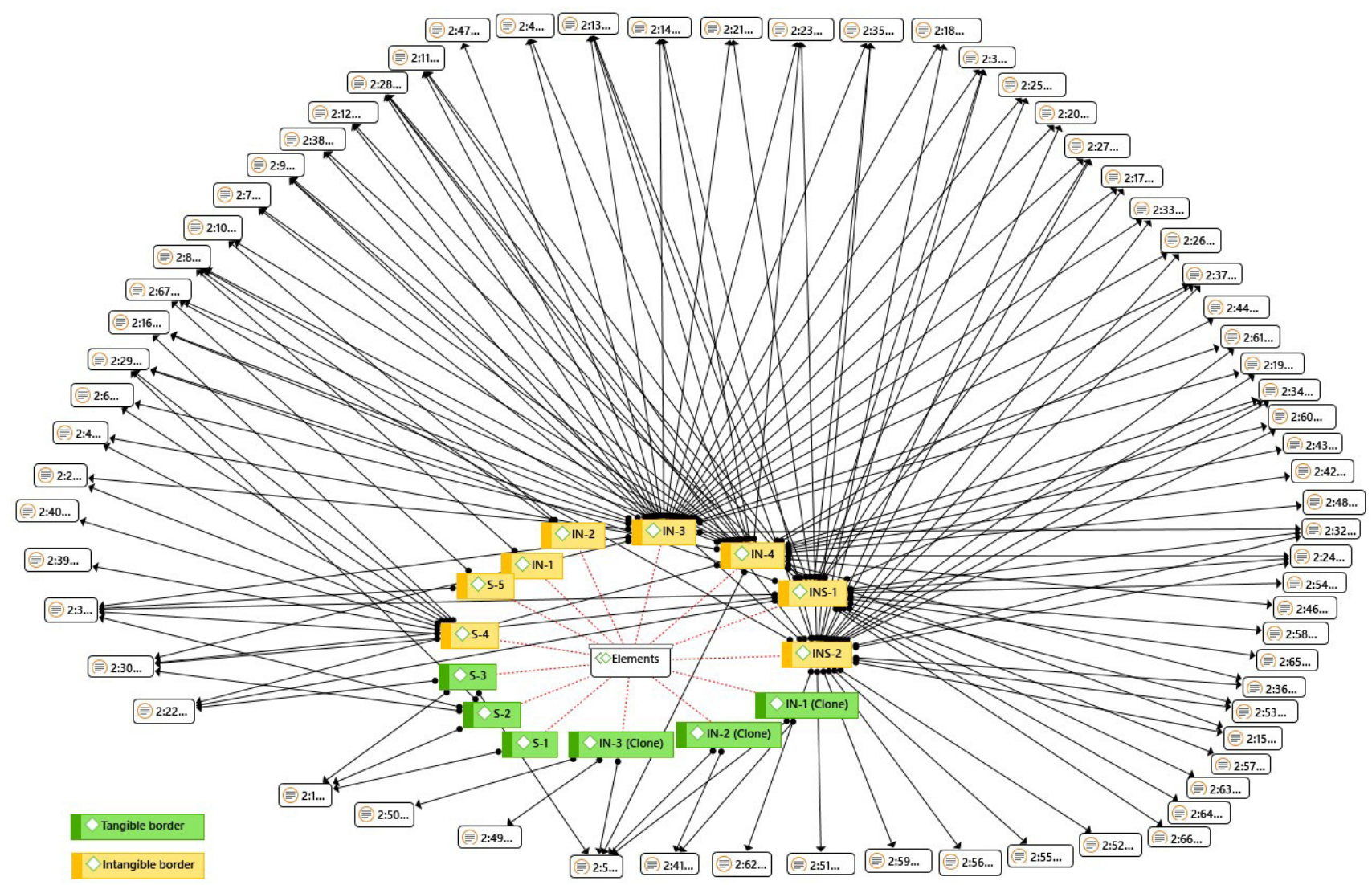

Figure 2. A network between codes and respondents' quotations. 
By looking at those lines, especially lines inside the code circle, we find that both tangible and intangible borders are linked by codes 'IN-4 Port-related values and ideas' and 'INS-1 Governance.' This is consistent with our above findings and has been verified by some of our examples. For instance, in the analysis of 'port-related people,' we have explained how 'IN-4-1 negative perceptions' harden the invisible, soft border and finally create tangible, hard borders between the port and the city. In the following section, we further investigate elements 'IN-4 Port-related values and ideas' and 'INS-1 Governance' to identify porosity for planning.

\subsection{Boundaries, Perception, and Planning}

As proposed in the theoretical discussion, the porosity for planning in border changes occurs around the penumbral, blurred outline between the port and the city. Thus, the identification of penumbral boundaries between the port and the city helps us better understand the role for planning. A relationship network of all codes from three layers and two borders is depicted in Figure 3. Six relations are generated based on the analysis of Table 2. 'Is associated with' and 'is part of' stand for basic relations between two objects; 'is a cause of' presents causal relations; 'positive interactions' presents mutual active influences; 'negative interactions' presents mutual passive influences; and 'contradicts' presents opposing, incompatible, or exclusive relations.

From left to right, Figure 3 displays tangible borders to intangible borders. As it shows, generally, the spatial layer (codes named as $\mathrm{S}-\mathrm{X}$ ) makes borders more tangible, while the institutional layer (codes named as INS-X) makes borders more intangible. The industrial layercodes named as IN-X and IN-X(Clone)-shifts between tangible and intangible, hard and soft boundaries. Thus, key elements in boundary changes should be in the industrial layer and the penumbral character can be found around those key elements. Considering two elements ('IN-4 Port-related values and ideas' and 'INS-1 Governance') from the last step, we initially identify that the key element is 'IN-4 Port-related values and ideas' and the exact penumbral character can be detailed in specific context. In Figure 3, 'IN-4' is made up of 'IN-4-1 Port-related values and ideas from non-harbour people' and 'IN-4-2 Port-related values and ideas from harbour people.' It seems assertive to make decisions in this way. However, we come to the same conclusion by looking into different relations.

In the relationship network, 'INS-1 Governance' represented as intangible borders does not connect with tangible borders directly. Besides, our identification that a penumbral perception can be found in port-related values and ideas is in line with our conceptual setting that penumbral comes from the field of psychology of perception and refers to a soft or blurred outline of a shadow. After confirming that 'penumbral' is around port-related values and ideas, we explain how a penumbral perspec- tive helps planning to change borders to connect the port and the city. Here is one example from a respondent:

What is the relationship between the port, portrelated industries, and our industrial park? It has nothing to do with us....This park is generally more than 8 kilometres away from the nearest port, even if the nearest point of this park is half a kilometre away from Luojing Port.... However [sic], if the water area inside the harbour can be allocated to our industrial park I think it would be really nice and then we can really enact industrial park evolution with the port development. I think we can really do it. Although ports are not directly related to us, we have manufacturing industries and we can connect this to cruise ship industry. (Baoshan Industrial Park manager)

Generally, this quotation shows how the port and the city can finally be connected with each other through changing borders. Border changes begin with: "However [sic], if the water area inside the harbour can be allocated to our industrial park." By saying this, the park management is authorised to partly govern the water area and water can be used for more than transporting goods. The respondent then continued that: "I think it would be really nice and then we can really enact industrial park evolution with the port development." Here, possibilities between the port and the park evolution are expected. Later, the respondent confirmed his proposal and added that "although ports are not directly related to us, we have manufacturing industries and we can connect this to cruise ship industry." By proposing this, collaborations between the port and the park are planned concretely and practically.

If we translate this process into our relationship network, it happens as follows: First, 'S-4 Distances' cause intangible borders between the port and the city (for more details see Section 3.2) which is reflected as 'contradicts' between 'S-4 Distances' and 'INS-2 Planning.' Second, 'the INS-1 Governance' of 'S-5 Water' causes changes of industrial park belonging to 'IN-4-1 Portrelated values and ideas from non-harbour people.' Third, an industrial park manager changes his negative views or perceptions on ports and port businesses and begins to expect possible cooperation between the port and the park evolution. Negative views here are mainly caused by 'S-4 Distances.' Namely, in this step, the line labelled as 'negative interactions' from 'IN-4-1' to 'INS-2' is changed as positive ones. Fourth, 'INS-2' causes specific developments of 'IN-3 Port-related activities.' As a result, collaborations the port and the city are developed.

Going back to the question before, the above example exemplifies how a penumbral perspective helps planning to change borders to connect the port and the city. In the above process, the port and the city are finally connected by 'INS-2' going to 'IN-3.' However, 'INS-2' is influenced by 'IN-4-1.' Moreover, intangible borders caused 


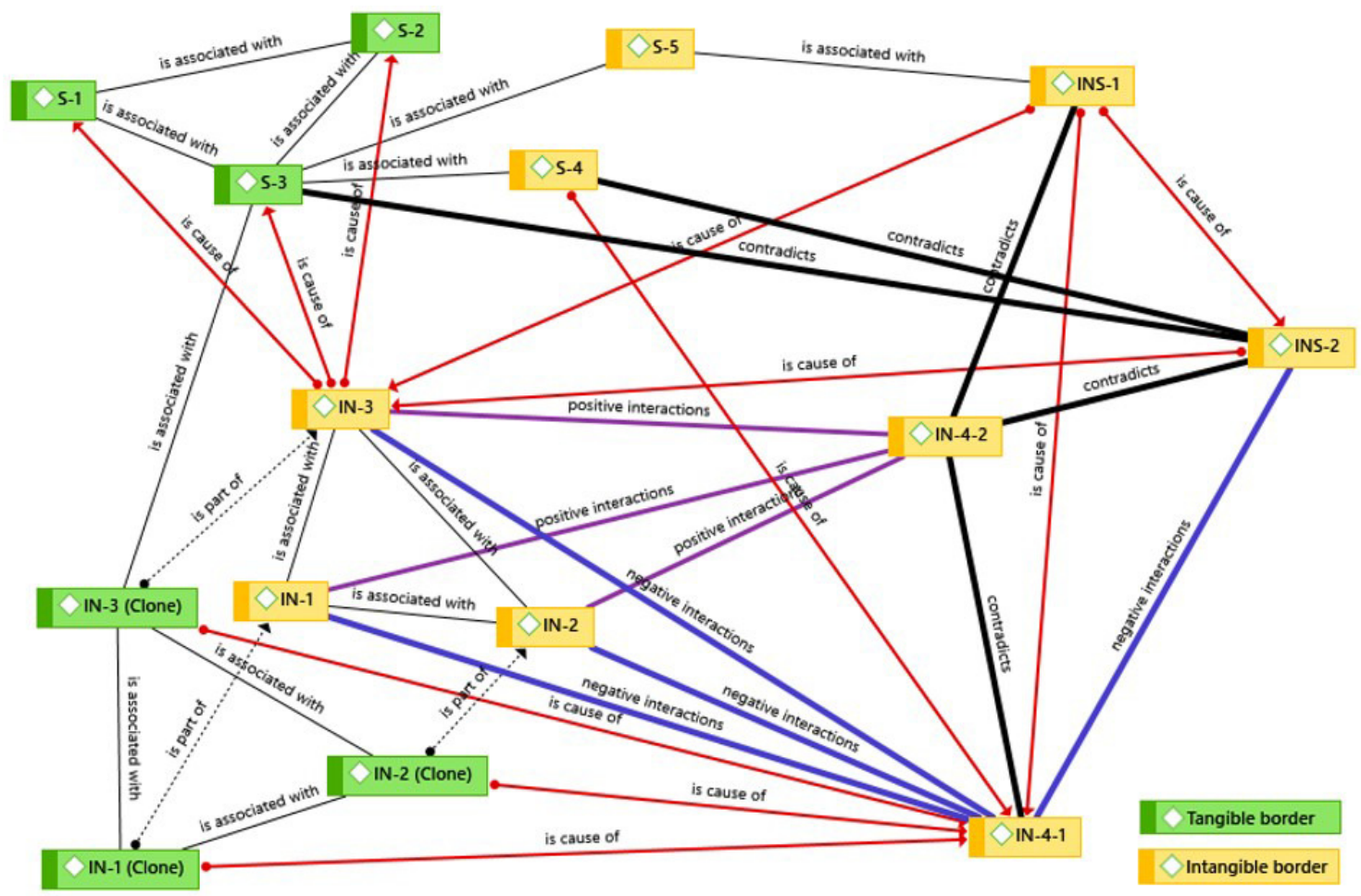

Figure 3. The relationship network between codes.

by 'S-4' are also changed by 'IN-4-1.' In other words: 'IN-4-1 Port-related values and ideas from non-harbour people' is particularly the perception that the port is not that far away from the industrial park. When this is recognised by the industrial park manager, he begins to expect possible collaboration opportunities between the port and the city. A later step emerges as a specific plan, connecting manufacturing industries with the cruise ship industry. This example demonstrates that a penumbral perspective is a precondition of specific development plan which changes borders and connects the port and the city concretely.

The above is just one example. If we look at Figure 3, there are multiple ways to change borders by planning with penumbral around 'IN-4 Port-related values and ideas.' They could include promoting positive relations to reduce or counteract passive relations, or improving or clearing up passive relations such as 'negative interactions' and 'contradicts' directly. For example, removing 'contradicts' between 'IN-4-2 Port-related values and ideas from harbour people' and 'INS-2 Planning.' According to the previous analysis in Section 3.2, more positive voices from harbour people can be included in the planning. This will lead positive changes to ' $I \mathrm{~N}-3$ Port-related activities.' Looking at lines around 'IN-3,' tangible and intangible borders are further re-connected and blurred. In the long term, the improved changes of tangible borders will cause positive changes to 'IN-4-1 Port-related values and ideas from non-harbour people,' where 'negative interactions' between it and 'IN-1,2,3' and 'INS-2' will be further improved. In the end, tangible and intangible borders across different layers will be weakened, and collaborations between the port and the city will enter a virtuous circle.

Thus, in changing borders to connect the port and the city, planning needs to first develop a penumbral perspective around 'IN-4 Port-related values and ideas,' and then apply this to specific development plans.

\section{Conclusions}

This article investigates changing tangible and intangible boundaries and the role of planning in border changes through a comprehensive analysis of spatial, industrial, and institutional elements, based on a case study of Baoshan port-city interface. Compared to previous port-city studies on tangible and intangible boundaries, we find that, besides spatial elements, tangible boundaries are also related to industrial aspects such as port-related goods, people, and activities. Regarding the formation of intangible borders, we add the elements of 'distances' and 'water.' Water always increases competition and conflict between the port and the city in the port-city interface literature since Hayuth (1982), though this element seems to be ignored in border studies. Our finding brings water back into the discussion and confirms that water does create intangible borders between the port and the city.

Taking spatial, institutional, and industrial aspects as three layers, our result confirms the declaration from Zimmerbauer (2011) that borders are deeply multilayered. As Paasi and Zimmerbauer (2016, p. 13) further argue that "while some layer might be highly permeable, other layer(s) can simultaneously make borders high 
and hard," we specify that the spatial layer makes borders more tangible because spatial elements like roads harden the border. While the institutional layer makes borders more intangible, because on the one hand, the current governance framework and land ownership in Shanghai cause the port to make weaker voices than the city, on the other hand current planning guidelines lead the port to a worsened situation and facilitate more negative perceptions on ports and port businesses. The industrial layer shifts between tangible and intangible, hard and soft borders. That is because industrial aspects such as port-related goods, people, and activities raise intangible borders between the port and the city; meanwhile, industrial aspects like negative perceptions on ports and port businesses create tangible borders by hardening the invisible, soft port atmosphere.

Our case exemplifies our conceptual summary that the porosity for planning in border changes occurs around the penumbral, blurred outline between the port and the city. First, based on a network between codes and respondents' quotations and a relationship network between codes, we verify that a penumbral perspective is constituted around port-related values and ideas. Second, using the example of Baoshan industrial Park, we further demonstrate how a penumbral perspective can help planning change borders to connect the port and the city. The Penumbral perception here is particularly presented in the statement that the port is "not being that far away" from the industrial park. Defining such blurred sphere, the industrial park manager begins to expect possible collaboration opportunities between the port and the city. Finally, a specific plan connecting manufacturing industries with the cruise ship industry is approached.

Thus, we claim that, in changing borders to connect the port and the city, planning needs first to pay attention to port-related values and ideas before creating specific development plans because boundaries are firstly changed by perceptions of actors. As analysed in the example of Baoshan Industrial Park, before taking what we would call a penumbral perspective, the manager concludes a totally different approach of the port and the city which emphasises that there is no relationship or possibility to facilitate collaborations between the and the city. However, accepting a penumbral perspective, the 'impossible' becomes 'possible' and even reasonable. Then, specific plans occur to make change or collaborations more concrete. In short, we point out that in the process of changing boundaries, planning needs to investigate such penumbral perspectives, especially how actors look at the port and port businesses carefully, and then planning can formulate specific plans as it usually does.

Furthermore, this article opens opportunities to investigate tangible and intangible border changes from a multi-layered perspective. Table 2 provides a conceptual framework of the comprehensive perspective and Figure 3 visualises the complicated relations embed- ded in three layers across two borders at the port-city interface. Specifically, Figure 3 can be used to guide plan-making empirically. In particular 'IN-4 Port-related values and ideas' seem to be a good starting point. They could promote positive relations to reduce or counteract passive relations, or improve or clear up passive relations such as 'negative interactions' and 'contradicts' directly. As the example of removing 'contradicts' between 'IN-4-2 Port-related values and ideas from harbour people' and 'INS-2 Planning' in Section 3.3 illustrates, in the end, tangible and intangible borders across different layers will be weakened, and collaborations between the port and the city will enter a virtuous circle, making the port-city interface a highly dynamic and constructive border space.

Though this article shows some promising outcomes, we recognise its limitations as a single case study in China. Our findings can be considered as preliminary and explorative, and need further testing in different contexts. Thus, we encourage researchers to investigate planning and multi-layered border changes with different port city practices based on our conceptual framework and findings in order to get a better understanding of the port-city interface as a penumbral zone that helps both the city and the harbour to 'see' and respond to internal and external challenges, and to plan and develop the port-city interface in a consistent and responsive manner.

\section{Acknowledgments}

The authors would like to thank all the respondents who generously participated in the interview and provided their insights. The authors also would like to express their gratitude to the Academic Editor and the three anonymous reviewers for their valuable suggestions.

\section{Conflict of Interests}

The authors declare no conflict of interests.

\section{References}

Allmendinger, P., \& Haughton, G. (2009). Soft spaces, fuzzy boundaries, and metagovernance: The new spatial planning in the Thames Gateway. Environment and Planning A: Economy and Space, 41(3), 617-633.

Association Internationale Villes et Ports. (2015). Plan the city with the port: Guide of good practices. https://www.aivp.org/en/publication/plan-the-citywith-the-port-guide-of-good-practices

Castells, M. (1996). The rise of the network society. Blackwell.

Compilation Committee of Records of Place Names in Shanghai. (1998). Shanghai diming zhi [Records of place names in Shanghai]. Shanghai Academy of Social Science Press. 
Daamen, T. A. (2010). Strategy as force: Towards effective strategies for urban development projects: The case of Rotterdam city ports [Doctoral thesis, Delft University of Technology]. Delft University of Technology Repositories. http://resolver.tudelft.nl/uuid: debd3977-828c-456c-b40c-6763a4a3453a

Daamen, T. A., \& Vries, I. (2013). Governing the European port-city interface: Institutional impacts on spatial projects between city and port. Journal of Transport Geography, 27, 4-13.

Hayuth, Y. (1982). The port-urban interface: An area in transition. Area, 14(3), 219-224.

Hein, C. (2011). Port cityscapes: A networked analysis of the built environment. In C. Hein (Ed.), Port cities: Dynamic landscapes and global networks (pp. 1-23). Routledge.

Hein, C. (2016). Port cityscapes: Conference and research contributions on port cities. Planning Perspectives, 31(2), 313-326.

Hein, C. (2019). The port cityscape: Spatial and institutional approaches to port city relationships. PORTUSplus, 8(Special issue). https://portusplus.org/index. php/pp/article/view/190/187

Hesse, M. (2013). Cities and flows: Re-asserting a relationship as fundamental as it is delicate. Journal of Transport Geography, 29, 33-42.

Hesse, M. (2018). Approaching the relational nature of the port-city interface in Europe: Ties and tensions between seaports and the urban. Tijdschrift Voor Economische En Sociale Geografie, 109(2), 210-223.

Hoyle, B. (1989). The port-city interface: Trends, problems and examples. Geoforum, 20(4), 429-435.

Hoyle, B. (2000). Global and local change on the port-city waterfront. Geographical Review, 90(3), 395-417.

Moretti, B. (2017). Port city borderscapes: Origin, nature and evolution of the administrative boundary. In G. Pellegri (Ed.), De-Sign environment landscape city (pp. 251-262). Polytechnic School of Genoa.

Müller, A.-L. (2016). 'European port cities' ambiance as heritage of the future: An analysis of Dublin and Gothenburg. Ambiances, tomorrow. Proceedings of 3rd International Congress on Ambiances, 2(Special issue), 945-950. https://hal.archives-ouvertes.fr/ hal-01414085/document

Norcliffe, G. B. (1981). Industrial change in old port areas, the case of the port of Toronto. Cahiers de géographie du Québec, 25(65), 237-253.

Paasi, A. (2010). Commentary. Environment and Planning A: Economy and Space, 42(10), 2296-2301.

Paasi, A., \& Zimmerbauer, K. (2016). Penumbral borders and planning paradoxes: Relational thinking and the question of borders in spatial planning. Environment and Planning A: Economy and Space, 48(1), 75-93.

Shanghai Baoshan District Historical Records Compilation Committee. (1996). Wusongqu zhi [Records of Wusong District]. Shanghai Academy of Social Science Press.

Shanghai Baoshan District Local Records Compilation
Committee. (1992). Baoshanxian zhi [Records of Baoshan County]. Shanghai People's Publishing House.

Shanghai Baoshan District People's Government and Shanghai Municipal Planning and Natural Resources Bureau. (2019). Shanghaishi Baoshanqu zongti guihua ji tudi liyong zongti guihua (2017-2035) [Baoshan Master plan 2017-2035]. Baoshan Disctrict Government.

Shanghai Municipality. (2016a). "Shisanwu" shiqi Shanghai guoji hangyun zhongxin jianshe guihua [Shanghai's 13th five-year plan (2016-2020) of international shipping centre]. Shanghai Municipal People's Government.

Shanghai Municipality. (2016b). Shanghaishi zonghe jiaotong "shisanwu" guihua [Shanghai's 13th five-year plan for comprehensive transportation]. Shanghai Municipal People's Government.

Slack, B. (1980). Technology and seaports in the 1980s. Tijdschrift Voor Economische En Sociale Geografie, 71(2), 108-113.

Swyngedouw, E. (2004). Scaled geographies: Nature, place, and the politics of scale. In E. Sheppard \& R. B. McMaster (Eds.), Scale and geographic inquiry (pp. 129-153). Blackwell.

Teschner, N. (2019). The battle over the commons in port cities. Urban Geography, 40(7), 918-937.

van den Berghe, K. (2018). Planning the port city: A contribution to and application of the relational approach, based on five case studies in Amsterdam (The Netherlands) and Ghent (Belgium) [Doctoral thesis, Ghent University]. Ghent University Academic Bibliography. http://hdl.handle.net/1854/LU-8575801

van den Berghe, K., \& Daamen, T. A. (2020). From planning the port/city to planning the port-city: Exploring the economic interface in European port cities. In A. Carpenter \& R. Lozano (Eds.), European port cities in transition: Strategies for sustainability (pp. 89-108). Springer.

Wang, H. (2014). Preliminary investigation of waterfront redevelopment in Chinese coastal port cities: The case of the eastern Dalian port areas. Journal of Transport Geography, 40, 29-42.

Wang, H., \& Luan, W. (2014). Guowai gangcheng binshuiqu zaikaifa yanjiu jinzhan yu qishi [Implication and progress of port-cities waterfront redevelopment studies abroad]. Areal Research and Development, 33(04), 13-18.

Wang, J. J., \& Slack, B. (2004). Regional governance of port development in China: A case study of Shanghai international shipping center. Maritime Policy \& Management, 31(4), 357-373.

Yin, R. K. (2018). Case study research and applications: Design and methods (6th edition). SAGE.

Zimmerbauer, K. (2011). Conceptualizing borders in cross-border regions: Case studies of the Barents and Ireland-Wales supranational regions. Journal of Borderlands Studies, 26(2), 211-229. 


\section{COGITATIO}

\section{About the Authors}

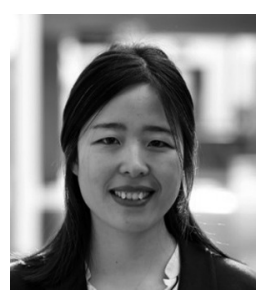

Yueyue Zhang is a PhD Candidate in the School of Management at Radboud University in the Netherlands. Her research focuses on the evolution of port cities, specifically, the port-city innovation ecosystem orchestration and maritime industrial innovations. For her PhD, she compares the Stadshaven (cityport) area in Rotterdam with Baoshan port-city interface in Shanghai.

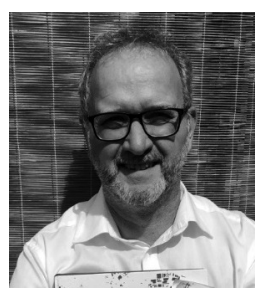

Peter Martin Ache (PhD) is Professor of Planning at Radboud University in Nijmegen, the Netherlands. $\mathrm{He}$ is a former President of AESOP and a Member of the ARL (Germany). His research interests are in strategic spatial planning, urban futures, foresight and back-casting, which he also covers in his teaching activities. 